De todos modos, seguí adelante con la búsqueda de este término en otras de sus obras. Gracias al ingenioso método del "buscador", me sorprendí al comprobar que Marx escribió "dictadura del proletariado" apenas diez veces a lo largo de toda su vida. Sólo lo hizo en un texto público — La lucha de clases en Francia-, las otras veces lo usó en cartas y documentos internos. Preocupado por la escasez de marxismo en la obra del propio Marx, apliqué el mismo método a las Obras Completas de Lenin. En el índice temático del tomo XLI de la edición de Cartago encontré citada la expresión "dictadura del proletariado" 186 veces y me quedé más tranquilo. El promedio de uso del término en relación a la totalidad de una obra subía de 0,00000001\% a 0,003\%. Sumando Marx + Lenin y dividiendo por dos, el promedio era aceptable. Pero la curiosidad me llevó a compulsar el término en las Obras completas de Stalin, y me encontré con que aparecía allí cientos de veces. Sólo en los Fundamentos del Leninismo Stalin utiliza la expresión en 92 ocasiones. ¿Habrá que rendirse ante la evidencia y concluir que Stalin era más marxista que Marx?

El problema de fondo es que nuestro impugnador no alcanza siquiera a vislumbrar que nuestra nota no era una síntesis pedagógica del pensamiento de Marx en sus propios textos, sino un esfuerzo por auscultar a través de una serie de signos y de síntomas cuál es el Marx que se lee ( $y$, por lo tanto, cuál otro no se lee) a comienzos del siglo XXI. Sin lugar a dudas, un ejercicio estéril para los fundamentalistas que consideran que los grandes sistemas teóricos atraviesan el tiempo y el espacio inmunes a cualquier contingencia. El marxismo sigue siendo para ellos un universal atemporal, abstracto, cerrado y autosubsistente. Todos los fundamentalismos son en definitiva religiosos porque su fin es resguardar la literalidad de los textos sagrados (o fundacionales), salvar la pureza de las ideas originarias de la contingencia de las interpretaciones. Piensan un poco como Vargas Llosa, tratando de establecer en qué momento se jodió el marxismo. Y se dedican a cortar las ramas secas del rosal esperando que alguna vez vuelva a florecer el tronco del marxismo-leninismo.

En suma, algunas derechas vociferaron, otras contemporizaron, otras callaron. Algunos populistas se sumaron como si nada a la celebración, otros se probaron las ropas de John William Cooke y se imaginaron en 2015 al frente de la Resistencia peronista de hace más de medio siglo. Para los fundamentalistas, se trató de preservar una momia de los riesgos de contaminación de la biósfera terrestre. Marx ha vuelto, pero como zombi.

Para nosotros fue una oportunidad de repensar a Marx, de reinventarlo a la altura de nuestros tiempos, de auscultarlo en los signos del presente. $Y$ como quiera que sea, el viejo barbado siguió dando que hablar, 200 años después.

\section{Historia reciente, historiografía y Justicia}

Hace ya algunos años, en una encuesta llevada a cabo por Políticas de la Memoria y publicada en su entrega $n^{\circ} 13$, Beatriz Sarlo decía algo así como que el rasgo distintivo de la cultura de izquierdas era el pensamiento crítico. Siguiendo a Sarlo, una intervención historiográfica desde la cultura de izquierdas no puede menos que implicar un análisis crítico tanto del pasado en general como del de las propias izquierdas en particular. Y esto último suele no ser tarea sencilla.

En el caso de la historia reciente, el ejercicio del pensamiento crítico pareciera muchas veces transitar sobre un territorio minado de irascibilidades reactivas en el que cualquier aproximación ajena al recorrido sacro de la reivindicación y el homenaje corre el riesgo de ser estigmatizado, bastardeado y condenado por un tribunal laxo pero no invisible que determina, sin leyes escritas, qué puede ser dicho y qué no.

Afortunadamente, nunca faltan oportunidades de demostrar que no es el pensamiento crítico sino su postergación aquello que puede empañar la historia y la suerte de las izquierdas. Y una de esas oportunidades la ofrece hoy el "caso Larrabure".

\section{Lo sintetizamos.}

El 11 de agosto de 1974, durante el asalto a la fábrica Militar de Pólvora y Explosivos de Villa María, Córdoba, el Ejército Revolucionario del Pueblo (ERP) secuestró al Mayor Argentino del Valle Larrabure, Subdirector de la Fábrica. Durante los siguientes tres meses, Larrabure permaneció secuestrado en una "cárcel del pueblo" en la provincia de Córdoba, para ser trasladado luego a otra "cárcel del pueblo" de la ciudad de Rosario.

Un año después de su secuestro, el 23 de agosto de 1975, el cuerpo sin vida del mayor Larrabure, con 47 kilos menos y signos de estrangulamiento aparecía en una esquina a las afueras de Rosario. Desde entonces, los familiares de Larrabure han acusado al ERP de aplicarle torturas durante su cautiverio y, finalmente, de asesinarlo. Por su parte, la organización guerrillera sostuvo en todo momento, también a través de declaraciones públicas, que no lo mató, sino que Larrabure, presa de un estado depresivo, se suicidó.

Tras la muerte de Larrabure se sustanciaron dos procesos judiciales. El primero, se vincula con el ataque al cuartel; alcanzó a los militantes del PRT-ERP que, directa o indirectamente, tuvieron algún grado de participación o responsabilidad en el secuestro del militar, y condujo a sentencias de entre 8 y 15 años de prisión. El

H.T. segundo, y más importante, es el vinculado a su muerte; se caratula "Larrabure, Argentino del Valle s/ su muerte" y fue tramitado 
ante Juzgado Federal $\mathrm{n}^{\circ} 1$ de la ciudad de Rosario. Este proceso no registra condenas y es el que ocupa hoy nuestra atención.

El 11 de octubre de 1977, el Juzgado resolvió sobreseer este proceso provisionalmente "dejándose el juicio abierto hasta la aparición de nuevos datos o comprobantes salvo el caso de prescripción". Como en el Código Penal argentino los delitos penados con prisión y reclusión perpetua — como el homicidio— prescriben a los 15 años de su comisión, la causa por la muerte de Argentino del Valle Larrabure, finalmente, prescribió. Pero su historia no terminó allí.

En febrero de 2007, en el contexto de la reapertura de los juicios por crímenes de lesa humanidad, el hijo del militar, Arturo Larrabure, solicitó al Juzgado que reabriera la causa entendiendo que la muerte de su padre se correspondía con la definición de delito de lesa humanidad presente en el Estatuto de Roma. El juez de primera instancia dio intervención al Fiscal general de la ciudad, Claudio Palacín, quien en su dictamen del 30 de octubre de 2007 advertía que "los crímenes contra la humanidad sufridos por Larrabure se cometieron en un contexto de conflicto armado interno". La causa llegó hasta la Unidad Fiscal de Coordinación y Seguimiento de las causas por violaciones de Derechos Humanos cometidas durante el terrorismo de Estado, dependiente de la Procuraduría General de la Nación. El 29 de noviembre de 2007, el entonces Procurador General de la Nación, Esteban Righi, determinó que, desde un punto de vista estrictamente jurídico, no corresponde aplicar a casos como el de Larrabure la categoría de crímenes de lesa humanidad y de crímenes de guerra, e instruyó a todos los fiscales con competencia penal que integran el Ministerio Público Fiscal de la Nación, que adoptaran dicha interpretación en todos los casos análogos.

Sin embargo, el caso Larrabure reiniciaría, diez años después, otra etapa que, a finales de 2019, no ha concluido.

En diciembre de 2017 la querella volvió a solicitar la reapertura de la causa y la prisión preventiva de Juan Arnol Kremer Balugano, más conocido como Luis Mattini, único sobreviviente del Buró político del PRT-ERP, por considerarlo "autor mediato" del delito de homicidio. El argumento replicaba los anteriores: se consideraba a Argentino del Valle Larrabure víctima de un delito de lesa humanidad en el contexto de un conflicto armado interno $y$, por tanto, imprescriptible. Rechazada en primera instancia, la solicitud llegó a la Cámara Federal de Apelaciones de Rosario quien atendió la solicitud de tratamiento y el 21 de marzo de 2018 tuvo lugar la audiencia de apelación. Sin expedirse afirmativa o negativamente ni en torno a la reapertura de la causa, ni en torno a la prisión preventiva de Mattini, la Cámara pasó a un prolongado cuarto intermedio. Finalmente, el 31 de agosto de 2018, ratificó el fallo por la negativa de primera instancia de diciembre de 2017. La querella entonces, apeló a la Cámara de Casación quien, el 10 de abril de 2019, declaró "inadmisible el recurso extraordinario" presentado. La siguiente instancia fue la presentación de queja a la Corte Suprema de Justicia quien aún no se ha expedido sobre la aceptación o el rechazo de su tratamiento.

El caso Larrabure ha tenido una repercusión pública considerable, fundamentalmente en marzo de 2018 cuando la Cámara de Apelaciones de Rosario aceptó tratar la solicitud de reapertura. El tema ocupó un espacio nada desdeñable en editoriales y columnas de opinión de los principales diarios del país; fue tratado por diversos programas radiales y convocó la intervención de intelectuales, de académicos, de organismos de derechos humanos y, por supuesto, de la militancia identificada con la causa revolucionaria y, también, con aquella conformada, fundamentalmente, por familiares de "víctimas de la subversión" y de ex represores, hoy procesados o condenados por delitos de lesa humanidad.

Los motivos de esta repercusión son evidentes: por un lado, la causa Larrabure sienta jurisprudencia; si se reabriera, podrían abrirse o reabrirse otras similares, y una cantidad indeterminada de ex integrantes de las organizaciones revolucionarias armadas podrían ser imputados ya sea como autores inmediatos, autores mediatos o partícipes necesarios de centenares de delitos. Por otro lado, y quizás más importante aún, la suerte de la causa impacta directamente en el espacio de la memoria social donde se dirimen las luchas políticas por imponer un sentido al pasado. Paralelamente, por muchos motivos, nos interpela en forma directa a los historiadores: la resolución jurídica del caso Larrabure, esto es, si los hechos vinculados a su secuestro y muerte se inscriben o no en la categoría de crímenes de lesa humanidad en el contexto de un conflicto armado interno - asimilable en el tratamiento jurídico a la figura de la guerra - no se juega tanto en el terreno del saber estrictamente jurídico, como en el del saber histórico que se necesita para dilucidar si son aplicables o no las mencionadas figuras jurídicas. Dicho en otras palabras, depende menos de tecnicismos jurídicos que de la interpretación de los hechos; esto es, si hubo o no una guerra; si el ERP constituía o no un ejército regular y/o controlaba territorio y población y, por tanto, su accionar es asimilable a una política estatal. En resumidas cuentas, si el ERP entra o no dentro del círculo de sujetos activos susceptibles de cometer crímenes de lesa humanidad.

Los historiadores sabemos que el PRT apeló a la figura de la guerra en su caracterización del proceso político; sabemos que fundó un ejército al que dotó de un himno y una bandera (el ERP); sabemos que proyectó el crecimiento de ese ejército con vistas a que alcanzase la estatura de un ejército regular; sabemos que en 1974, a través de un conjunto de normativas, el ERP regularizó sus fuerzas, estableciendo el uso obligatorio de uniforme, grados y códigos disciplinarios; sabemos que a partir de entonces no sólo exigió, a través de declaraciones públicas, el cumplimiento de las Convenciones de Ginebra sino también el reconocimiento 
como "estado beligerante"; y sabemos finalmente que luego de la apertura de un frente militar en la provincia de Tucumán, concibió a aquel territorio como "zona liberada".

Como ha quedado demostrado en los fundamentos de querellantes, fiscales y jueces en las distintas instancias de la causa Larrabure, del análisis de estos datos, de su interpretación, depende, en buena medida, la resolución de la causa.

Para que la causa Larrabure sea considerada imprescriptible, la muerte del militar debe quedar inscripta en la categoría de "crimen de lesa humanidad en el contexto de conflicto armado interno". A tal fin, la querella debe demostrar que en la Argentina de los años setenta hubo una guerra, que el ERP constituyó uno de los ejércitos regulares enfrentados en esa guerra, y que, además, controlaba territorio y población. Y es aquí, entonces, donde nos encontramos, no sin sorpresa, con una interesante paradoja. Las fuentes en las que se basa la querella en su fundamentación están compuestas, en porcentaje mínimo, por la propia documentación partidaria y, en un porcentaje notoriamente mayor, por la obra de un reconocido historiador del PRT-ERP, Pablo Pozzi, a quien de ninguna manera podría considerarse ni remotamente aliado de la querella. El problema es que, más allá de la reconstrucción particular de la experiencia perretista que Pozzi ofrece y su ponderación, más allá de su propia voluntad incluso, el tono general de la obra no logra trascender el sistema partidario de creencias. Los testimonios allí reproducidos, abundantes en guiños de complicidad y escasos en confrontación crítica, empujan a una narrativa que no deja de hacerse eco de las proyecciones imaginarias de los propios actores. $Y$ entonces, nos encontramos ante un PRT-ERP con una influencia de masas y una capacidad política y militar un tanto sobredimensionadas, incluso en Tucumán, donde, según "un informe de la Fuerza Aérea norteamericana", mencionado pero nunca confrontado por Pozzi, el ERP controlaba un tercio del territorio. Y es ahí donde la querella echa mano de la autoridad del historiador y ofrece como prueba histórica lo que no es más que imaginario.

En contraposición, sólo un abordaje crítico, irreverente, que sea capaz no sólo de ver el mundo con los ojos de los revolucionarios sino también de trascender esa mirada, despegarse de ella y ver lo que esos ojos no pueden ver; un abordaje que interpele a sus propias fuentes, que sepa desconfiar de ellas, puede —al menos en este caso, aunque lo más probable es que en otros tambiéndiscernir proyecciones imaginarias, por empáticas que nos resulten, de realidades históricas que no pueden reducirse nunca a ellas puesto que - aun con independencia de datos empíricosimplican procesos complejos que resultan de la interacción de múltiples sujetos y de variadas intencionalidades en pugna. Y, en consecuencia, sólo un abordaje tal puede constituir argumento y prueba para que la disparidad y la diferencia históricas entre la violencia represiva y la revolucionaria encuentre su paralelismo en el campo jurídico; máxime en una sociedad en la que la voz de la Justicia ha marcado, en buena medida, los tiempos, el tono y el lenguaje de la memoria social.

Por añadidura, en el caso particular que nos ocupa, sólo aquellas intervenciones que desafiando el poder de veto realmente existente se adentren en el estudio de uno de los temas tabú por excelencia, el de la "justicia revolucionaria" — cuyas prácticas más conflictivas fueron los secuestros extorsivos y las ejecuciones selectivas de personas - pueden ofrecer argumentos tendientes a demostrar, a través de la investigación empírica y el análisis riguroso, que es más plausible, en relación al hecho que se juzga (esto es, la muerte de Larrabure), que la verdad se encuentre en boca del PRT-ERP y no en la de los deudos del militar. Dicho en otras palabras, que la organización guerrillera ni torturó a Larrabure (porque la guerrilla argentina no tortura), ni lo mató (porque cuando mata, justamente porque lo considera un acto de justicia, lejos de negarlo, lo reivindica).

En fin, el caso Larrabure, nos invita no sólo a repensar el complejo vínculo entre Historia y Justicia, también a redoblar la apuesta por una historiografía crítica de las izquierdas, aunque más no sea en el más elemental y modesto gesto del oficio: la distancia entre objeto y sujeto de conocimiento. Está claro que esa criticidad puede no ser exclusiva de la cultura de izquierdas, pero es, en todo caso, su condición sine quanon.

V. C.

\section{Memorias para los feminismos}

Así como la acción de apertura del Teatro Cervantes en 2018 tomó a Marx como referencia, el 2019 abrió con una Asamblea de Mujeres que retomaba el título de aquella vieja obra de Aristófanes. A la hora del cierre, que compartimos con Diana Maffía y Rita Segato, la sala no podía estar más colmada ni más verde. El programa de todo el día había intentado — no sin una esperable cuota de fracaso- captar todas las inflexiones del deseo y la identidad, con el objetivo de demostrar que la asamblea del siglo XXI debe ser diversa, disidente, y plural en voces y cuerpos.

El panel final nos propuso responder la pregunta "¿Cómo vivir juntes?", un interrogante que sonaba algo paradójico bajo un gobierno en el cual las condiciones de vida fueron cada vez más precarias y excluyentes. Porque, a pesar de su reconocida autonomía, el Cervantes no dejaba de ser un teatro de gestión estatal y, por tanto, resultaba pertinente responder con una crítica explícita a las formas de vida propuestas a fuerza de profundizar el neoliberalismo y sus verdades. Una suma de eslóganes entre cuyos 